\title{
Generalised Anxiety Disorder, Mortality and Disease: A Stronger Predictor than Major Depressive Disorder
}

\author{
Anna C. Phillips \\ University of Birmingham, School of Sport E Exercise Sciences
}

UK

\section{Introduction}

This chapter will examine the associations between Generalised Anxiety Disorder (GAD) and key health outcomes, including mortality, the metabolic syndrome, and hypertension, citing relevant research and recent findings from the Vietnam Experience Study. It aims to show that GAD is as strong a determinant of such health outcomes, if not a stronger one than MDD. It also aims to illustrate the importance of considering the comorbidity of GAD with other psychiatric diagnoses when predicting mortality and other health outcomes.

\section{GAD and mortality}

Mental health disorders in the general population are relatively common (Kessler et al., 2005; Kessler, Chiu, Demler, Merikangas, \& Walters, 2005). In fact, an estimated $14 \%$ of the global disease burden has been attributed to mental health disorders (World Health Organisation, 1992-1994), and this figure is likely to be an underestimate as it fails to take into consideration the association between mental health and other health conditions (Prince et al., 2007). Populations who have been exposed to traumatic events, such as war veterans, have an even higher prevalence of Generalised Anxiety Disorder (GAD) and Major Depressive Disorder (MDD) (Gaylord, 2006; Hoge, Auchterlonie, \& Milliken, 2006; Reeves, Parker, \& Konkle-Parker, 2005). For example, soldiers assessed a few months after returning from deployment to Afghanistan and Iraq had a GAD prevalence of around $14 \%$ and $15 \%$, respectively, and prevalence of MDD of around 17\% and 16\% (Hoge et al., 2004). Others have reported depressive symptom rates as high as $19 \%$ in veterans based on prior diagnosis records (Kinder et al., 2008), and 31\% using self-report measures (Hankin, Spiro, Miller, \& Kazis, 1999), although some studies have shown lower rates of $6.9 \%$ and $1.7 \%$ for MDD and GAD, respectively (Sareen et al., 2007). Little has been reported about the consequences for survival of these mental health disorders in veterans.

In the general population, MDD has been associated with increased mortality rates (see e.g. O'Leary \& Lee, 1996; Surtees \& Barkley, 1994). Although much of this excess is attributable to non-medical causes of death such as injury and suicide, it is becoming clear that MDD also increases the risk of death from common chronic diseases such as cardiovascular disease (CVD) (Osby, Brandt, Correia, Ekbom, \& Sparen, 2001). There is now substantial evidence linking depression with CVD morbidity and mortality (see e.g. Musselman, Evans, 
\& Nemeroff, 1998; Wulsin, Vaillant, \& Wells, 1999). However, much of this research has examined the impact of depressed mood rather than a diagnosis of MDD. In a recent metaanalysis of 11 studies of coronary heart disease (CHD), MDD, which had been measured in only three studies, was a much stronger predictor of CHD outcomes than depressed mood (Rugulies, 2002). Few studies have examined GAD as a risk factor for all-cause mortality, although two population studies suggest that, for causes of death other than suicide, GAD does not present a significant risk (Holwerda et al., 2007; Murphy, Monson, Olivier, Sobol, \& Leighton, 1987). However, other manifestations of anxiety have been associated with an increased risk of CVD morbidity and/or mortality (see e.g. Eaker, Sullivan, Kelly-Hayes, D'Agostino, \& Benjamin, 2005; Haines, Imeson, \& Meade, 1987; Weissman, Markowitz, Ouellette, Greenwald, \& Kahn, 1990). It would appear that no studies have measured the relationship between diagnosed GAD and CVD mortality.

The bulk of research examining the consequences of mental health disorders for chronic disease in veterans has concentrated on post-traumatic stress disorder (PTSD). For example, lifetime prevalence of PTSD was linked with an increased mortality rate (Boscarino, 2006a, 2006b). In addition, PTSD in veterans has also been associated with cardiovascular, digestive, musculoskeletal, endocrine-nutritional-metabolic, nervous system, respiratory, and nonsexually transmitted infectious diseases (J.A. Boscarino, 1997), chronic changes in immunity (Boscarino \& Chang, 1999), and markers of inflammatory disorders (Boscarino, 2004). However, there appear to be few studies examining the influence of other major mental health disorders on mortality risk in veterans. In a study of PTSD and MDD in veterans, MDD was related to increased mortality following adjustment for age, demographic variables, health behaviours, and medical co-morbidities (Kinder, et al., 2008). The association between GAD and mortality in veterans does not appear to have been studied.

Given the reported high prevalence of GAD and MDD in army veterans and the significant prevalence of these disorders in the general population, their individual and combined impact merits research attention. Recently, it was possible to address this issue in the Vietnam Experience Study.

\subsection{The Vietnam experience study}

The Vietnam Experience Study is an epidemiological study commissioned by the US congress to investigate the health consequences of the military experiences of Vietnam veterans. The participants were male military personnel drawn from approximately five million US Vietnam-era army veterans whose service files were stored at the National Personnel Records Center (Vietnam Experience Study, 1987). The Centers for Disease Control, Atlanta, had access to U.S. Veteran Administration records and provided a fully anonymised dataset. Those who entered military service between January 1, 1965 and December 31, 1971; served only one term of enlistment; served at least 16 weeks of active duty; earned a military specialty other than "trainee" or "duty soldier"; at discharge from active duty had a military pay grade no higher than sergeant; and had not died during military duties were eligible for inclusion. On reviewing a random sample of 48513 records, 1355 were found to be incomplete, 28577 did not meet study entry criteria and 268 men died during military duties, so the final cohort included 18,313 former military personnel. Of those included in the original cohort, 17,867 were considered to be alive on December 31st 1983 and therefore eligible for active follow-up.

Information pertaining to place of service, military rank, ethnicity, and cognitive ability scores from the Army General Technical Test (hereafter referred to as "IQ") was extracted 
from the military archives. Participants were designated as being Vietnam veterans if they had served at least one tour of duty in Vietnam, and as non-Vietnam veterans if they did not (this group included men who served one or more tours of duty in Korea, Germany or the US). The ethnic origin of the study members were classified as 'white', 'black', or 'other'; the latter group comprising Hispanics, Asians, Pacific Islanders, American Indians, and Alaskan Natives.

In 1985 these participants were invited to participate in a telephone interview. Telephone directories, credit bureau searches, driver's license and motor vehicle registration records, city directories, local records and personal field visits were all utilized to locate the whereabouts of apparently surviving men. Of those traced $(\mathrm{N}=16349)$, an interview was not possible for reasons of incarceration $(\mathrm{N}=63)$, physical or mental disability $(\mathrm{N}=20)$, refusal $(\mathrm{N}=949)$, death during the tracing process $(\mathrm{N}=53)$, or 'other' $(\mathrm{N}=6)$. This resulted in a sample of 15,288 men $(85.6 \%$ of those alive on December 31st 1983) who participated in the 1985 telephone survey (Batty et al., 2008). During the telephone survey, enquiries were made about the study participants' socio-economic characteristics, health behaviours, and health. Socio-economic position was measured using household income in midlife. Frequency of alcohol consumption was classified as number of units consumed per week. Smoking habits and marital status were ascertained using standard questions. Participants were also asked whether or not they had a range of somatic physician-diagnosed health problems which included hypertension, cancer, diabetes and coronary heart disease (The Centers for Disease Control Vietnam Experience Study., 1988a, 1988b).

In 1986, a random sample of telephone interview respondents $(\mathrm{N}=6443)$ were invited to attend a three day medical examination with orientation at a single facility in Albuquerque, New Mexico, for which travel expenses and a nominal stipend were met; 4462 attended $(69.3 \%$ of those invited). The mean age at medical examination was 38.3 years (range: 31.1 to 49.0 ). Of those invited, medical examination was not possible for reasons of incarceration $(\mathrm{N}=26)$, physical or mental disability $(\mathrm{N}=10)$, refusal $(\mathrm{N}=949)$, death before invitation $(\mathrm{N}=10)$, or 'refusal' $(\mathrm{N}=372)$. The main reasons for refusing to participate at this stage of data collection were: work related, e.g. unable to get leave with pay; a lack of interest in the study, e.g. unable to see how it would benefit them; or personal, e.g. did not like to travel. The final number of participants with complete data after the medical examination was 4256 . This group represents $23.3 \%$ of persons originally enrolled in the study. Sampling in the study is shown in Figure 1, below. For the medical examination, all men were requested to fast from 19.00 the evening before medical testing. Following the drawing of blood the following morning, cholesterol level was ascertained using a Kodak Ektachem 700 autoanalyzer (The Centers for Disease Control Vietnam Experience Study., 1988a, 1988b). Serum glucose level was determined with a standard adaptation of the glucose oxidase-peroxidase-chromogen-coupled system for glucose determination in biologic fluids (The Centers for Disease Control Vietnam Experience Study., 1988a, 1988b). Blood pressure, while seated, was measured twice in the right arm using a standard mercury sphygmomanometer; for the purposes of analyses, an average was computed. Height and weight, measured using standard protocols, were used to calculate body mass index (BMI) $\left(\mathrm{kg} / \mathrm{m}^{2}\right)$.

\subsubsection{Psychological morbidity}

Psychological morbidity was assessed using the Diagnostic Interview Schedule (version 3A) as administered by a trained psychological technician. The Diagnostic Interview Schedule is 


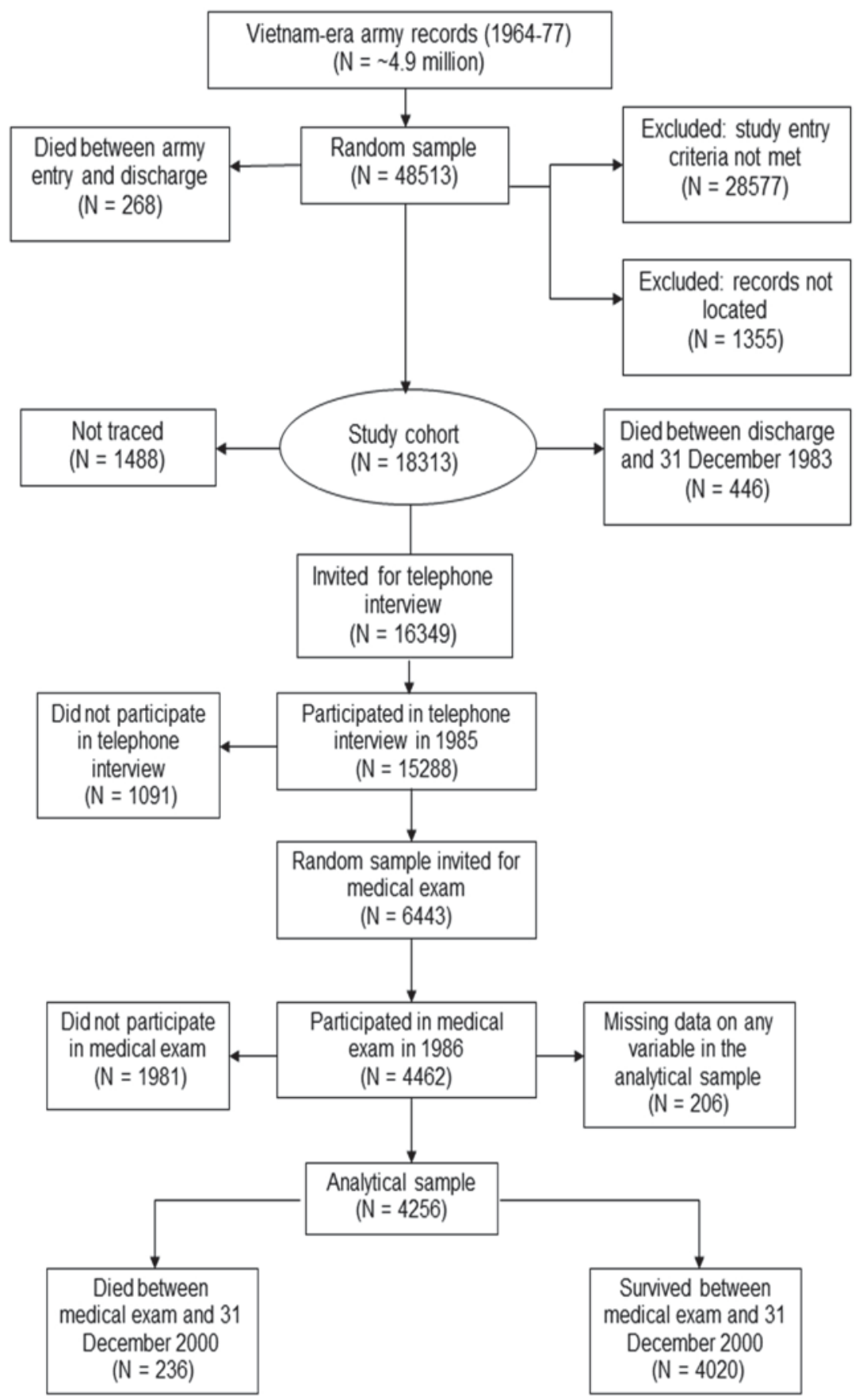

Fig. 1. Sampling in the Vietnam Experience Study 
a standardized questionnaire that is designed to assess the prevalence of certain psychiatric conditions according to the Diagnostic and Statistical Manual of Mental Disorders (version III) criteria of the American Psychiatric Association (APA, 1980; Robins, Helzer, \& Cottler, 1987). Study participants were considered positive for GAD and MDD if they reported a pattern of symptoms in the previous 12 months that satisfied full Diagnostic and Statistical Manual of Mental Disorders (version III) criteria. Characteristics of those with and without a diagnosis of GAD are shown in Table 1.

\begin{tabular}{|c|c|c|c|c|c|}
\hline & \multicolumn{2}{|c|}{$\begin{array}{l}\text { Generalised } \\
\text { Anxiety } \\
\text { Disorder } \\
(\mathrm{N}=411)\end{array}$} & \multicolumn{2}{|c|}{$\begin{array}{l}\text { No Generalised } \\
\text { Anxiety } \\
\text { Disorder } \\
(\mathrm{N}=3845)\end{array}$} & \multirow[t]{2}{*}{$p$} \\
\hline & Mean & SD & Mean & SD & \\
\hline Standardised IQ score from enlistment & 96.5 & 16.18 & 101.9 & 14.99 & $<.001$ \\
\hline Units of alcohol per week & 10.6 & 22.87 & 6.7 & 13.15 & $<.001$ \\
\hline Age at medical examination (years) & 38.0 & 2.65 & 38.4 & 2.50 & .003 \\
\hline Total cholesterol $(\mathrm{mmol} / \mathrm{l})$ & 5.5 & 1.01 & 5.5 & 1.09 & .42 \\
\hline Blood glucose (mg/dL) & 95.6 & 20.44 & 94.2 & 16.66 & .10 \\
\hline SBP (mmHg) & 123.8 & 13.06 & 122.9 & 11.93 & .17 \\
\hline \multirow[t]{2}{*}{ BMI $(\mathrm{kg} / \mathrm{m} 2)$} & 25.9 & 3.70 & 25.9 & 4.12 & .88 \\
\hline & \multicolumn{2}{|c|}{$\mathrm{N}(\%)$} & \multicolumn{2}{|c|}{$\mathrm{N}(\%)$} & $p$ \\
\hline $\begin{array}{c}\text { Ever in Vietnam } \\
\text { Other overseas } \\
\text { US only }\end{array}$ & \multicolumn{2}{|c|}{$\begin{array}{l}267(65) \\
85(21) \\
59(14)\end{array}$} & \multicolumn{2}{|c|}{$\begin{array}{c}2082(54) \\
1010(26) \\
753(20)\end{array}$} & $<.001$ \\
\hline $\begin{array}{l}\text { White } \\
\text { Black } \\
\text { Other }\end{array}$ & \multicolumn{2}{|c|}{$\begin{array}{l}311(76) \\
61(15) \\
39(9)\end{array}$} & \multicolumn{2}{|c|}{$\begin{array}{c}3179(83) \\
435(11) \\
231(6)\end{array}$} & .001 \\
\hline $\begin{aligned} \text { Household income in midlife } & <\$ 20,000 \\
& -\$ 40,000 \\
& >\$ 40,000\end{aligned}$ & \multicolumn{2}{|c|}{$\begin{array}{l}184(45) \\
171(42) \\
56(13)\end{array}$} & \multicolumn{2}{|c|}{$\begin{array}{l}1018(26) \\
1958(51) \\
869(23)\end{array}$} & $<.001$ \\
\hline $\begin{array}{r}\text { Non smoker } \\
\text { Ex smoker } \\
\text { Current smoker }\end{array}$ & \multicolumn{2}{|c|}{$\begin{array}{c}79(19) \\
90(22) \\
242(59)\end{array}$} & \multicolumn{2}{|c|}{$\begin{array}{l}1006(26) \\
1119(29) \\
1720(45)\end{array}$} & $<.001$ \\
\hline $\begin{array}{rr}\text { Marital Status: } & \text { Married } \\
\text { Divorced/separated/widowed } & \text { Never married }\end{array}$ & \multicolumn{2}{|c|}{$\begin{array}{l}244(59) \\
116(28) \\
51(12)\end{array}$} & \multicolumn{2}{|c|}{$\begin{array}{c}2887(75) \\
651(17) \\
307(8)\end{array}$} & $<.001$ \\
\hline $\begin{array}{ll}\text { Physical Illness } & \text { No } \\
\text { diabetes/hypertension/cancer or CHD } & \text { Yes }\end{array}$ & \multicolumn{2}{|c|}{$\begin{array}{c}335(82) \\
76(18)\end{array}$} & \multicolumn{2}{|c|}{$\begin{array}{c}3349(87) \\
496(13)\end{array}$} & .002 \\
\hline
\end{tabular}

Table 1. Characteristics of those with and without a diagnosis of GAD

\subsubsection{Mortality status}

The vital status of men between army discharge and December 31st 1983 (the date the cohort was established) was ascertained by cross-checking against a variety of mortality databases supplied by the US army, the Veterans Administration (Beneficiary Identification 
and Records Locator Subsystem), the Social Security Administration, the Internal Revenue Service, and the National Center for Health Statistics (National Death Index). Vital status post-medical exam continued to be ascertained until 31st December 2000 using the same mortality databases. Mortality due to major CVD was classified using the International Classification of Diseases (ICD) (World Health Organisation, 1992) codes: ICD-9: 390434,436-448, and ICD-10: I00-I78 which comprised: acute rheumatic fever; chronic rheumatic heart diseases; hypertensive diseases; ischaemic heart diseases; pulmonary heart disease and diseases of pulmonary circulation; other forms of heart disease; cerebrovascular diseases; diseases of arteries, arterioles and capillaries. The CVD mortality variable thus encompasses death from a variety of disorders.

\subsection{Characteristics of those with GAD and who were deceased}

Of the 4256 participants, 9.7\% for GAD and 6.5\% met diagnostic criteria for MDD. GAD was significantly associated with serving in Vietnam, younger age at the time of the medical examination, being non-white, and equally likely to be divorced/separated/widowed as never married. These individuals also had lower IQ scores, and lower household income in mid life. Finally, they were more likely to be a current smoker and to drink more units of alcohol per week; and were more likely to have a physical illness. During the 15 years of follow-up there were 236 deaths. Higher mortality was associated with service in Vietnam, not being married, being non-white, having lower household income in midlife, higher blood pressure and blood glucose level, smoking; higher alcohol consumption, and reported physical illness at examination. The characteristics of those who were and were not deceased are shown in Table 2.

\subsection{Associations with mortality}

Following adjustment for age and the other covariates measured, described above in section 2.1 and shown in Table 1, it was found that both those with GAD and those with MDD were at an increased risk of death during follow-up. This risk of all-cause mortality was roughly 1.6 times greater than that of those with no diagnosis. However, the effect for GAD was stronger than that for MDD. In analyses using cardiovascular disease mortality as the outcome, adjusting for confounding variables, neither GAD nor MDD were related increased risk of death, although the associations were in the same direction as for all-cause mortality.

Interestingly, 153 (3.6\%) of participants had a diagnosis of both MDD and GAD in the past year. In fully adjusted analyses, simultaneously using comorbidity as a predictor variable as well as MDD or GAD alone, only comorbidity was significantly related to both all-cause and cardiovascular disease mortality. These differences between the diagnoses groups and risk of death are shown in Figure 2.

The prevalence of GAD and MDD are higher than general population estimates (Kessler, Chiu, et al., 2005). However, even higher prevalence has been observed in other veteran groups when mental disorders were measured more proximally to combat exposure (Hoge, et al., 2004). Undoubtedly the most compelling and robust associations with mortality, both all-cause and CVD, emerged for MDD and GAD comorbidity. The present results regarding GAD contrast with those from the two previous studies on GAD and all-cause mortality, which suggest that GAD does not present a significant risk (Holwerda, et al., 2007; Murphy, et al., 1987). However, this discrepancy might be due to the difference in populations 


\begin{tabular}{|c|c|c|c|c|c|}
\hline & \multicolumn{2}{|c|}{$\begin{array}{l}\text { Died: All-cause } \\
\qquad(\mathrm{N}=236)\end{array}$} & \multicolumn{2}{|c|}{$\begin{array}{l}\text { Surviving } \\
(\mathrm{N}=4020)\end{array}$} & \multirow[t]{2}{*}{$p$} \\
\hline & Mean & SD & Mean & SD & \\
\hline Standardised IQ score from enlistment & 96.5 & 15.2 & 101.6 & 15.14 & $<.001$ \\
\hline Units of alcohol per week & 11.9 & 23.00 & 6.8 & 13.7 & $<.001$ \\
\hline Age at medical examination (years) & 38.6 & 2.68 & 38.3 & 2.51 & .15 \\
\hline Total cholesterol $(\mathrm{mmol} / \mathrm{l})$ & 5.6 & 1.35 & 5.5 & 1.06 & .45 \\
\hline Blood glucose (mg/dL) & 102.6 & 40.75 & 93.8 & 14.38 & $<.001$ \\
\hline $\mathrm{SBP}(\mathrm{mmHg})$ & 125.4 & 15.65 & 122.9 & 11.79 & .001 \\
\hline \multirow[t]{2}{*}{$\mathrm{BMI}\left(\mathrm{kg} / \mathrm{m}^{2}\right)$} & 25.9 & 3.69 & 26.2 & 4.50 & .20 \\
\hline & \multicolumn{2}{|c|}{$\mathrm{N}(\%)$} & \multicolumn{2}{|c|}{$\mathrm{N}(\%)$} & $p$ \\
\hline $\begin{array}{c}\text { Ever in Vietnam } \\
\text { Other overseas } \\
\text { US only }\end{array}$ & \multicolumn{2}{|c|}{$\begin{array}{l}148(63) \\
49(21) \\
39(17) \\
\end{array}$} & \multicolumn{2}{|c|}{$\begin{array}{l}2201(55) \\
1046(26) \\
773(19)\end{array}$} & .06 \\
\hline $\begin{array}{cc}\text { Ethnicity: } & \text { White } \\
& \text { Black } \\
& \text { Other } \\
\end{array}$ & \multicolumn{2}{|c|}{$\begin{array}{l}162(69) \\
51(21) \\
23(10)\end{array}$} & \multicolumn{2}{|c|}{$\begin{array}{c}3328(83) \\
445(11) \\
247(6)\end{array}$} & $<.001$ \\
\hline $\begin{aligned} \text { Household income in midlife } & <\$ 20,000 \\
& -\$ 40,000 \\
& >\$ 40,000\end{aligned}$ & \multicolumn{2}{|c|}{$\begin{array}{c}110(47) \\
105(44) \\
21(9)\end{array}$} & \multicolumn{2}{|c|}{$\begin{array}{c}1092(27) \\
2024(50) \\
904(23)\end{array}$} & $<.001$ \\
\hline $\begin{array}{lr}\text { Smoking Status: } & \text { Non } \\
\text { smoker } & \text { Ex smoker } \\
& \text { Current smoker } \\
\end{array}$ & \multicolumn{2}{|c|}{$\begin{array}{c}42(18) \\
44(19) \\
150(64)\end{array}$} & \multicolumn{2}{|c|}{$\begin{array}{l}1043(26) \\
1165(29) \\
1812(45)\end{array}$} & $<.001$ \\
\hline $\begin{array}{rr}\text { Marital Status: } & \text { Married } \\
\text { Divorced/separated/widowed } & \text { Never married } \\
\end{array}$ & \multicolumn{2}{|c|}{$\begin{array}{l}129(55) \\
71(30) \\
36(15)\end{array}$} & \multicolumn{2}{|c|}{$\begin{array}{c}3002(75) \\
696(17) \\
322(8) \\
\end{array}$} & $<.001$ \\
\hline $\begin{array}{ll}\text { Physical Illness } & \text { No } \\
\text { diabetes/hypertension/cancer or CHD } & \text { Yes }\end{array}$ & \multicolumn{2}{|c|}{$\begin{array}{c}62(26) \\
174(74)\end{array}$} & \multicolumn{2}{|c|}{$\begin{array}{l}3510(87) \\
510(13)\end{array}$} & $<.001$ \\
\hline
\end{tabular}

Table 2. Characteristics of those who were and were not deceased

examined: older adults (Holwerda, et al., 2007) and the general population (Murphy, et al., 1987). It is also possible that anxiety may only predict mortality in men, as in one previous study where an association between anxiety disorders and mortality was found for men but not women (van Hout et al., 2004). GAD has not been previously studied in terms of CVD mortality in the general population, or in the context of mortality per se in veterans. This seems unfortunate given that it is a strong predictor of all-cause mortality in the present analyses. The present findings are consistent with the results of previous research linking MDD with all-cause mortality in the general population (e.g. O'Leary \& Lee, 1996; Surtees \& Barkley, 1994) and in veterans (Kinder, et al., 2008). Although many studies have considered depression as a predictor of CVD mortality, surprisingly few have examined diagnosed MDD. Of those available, both positive (Osby, et al., 2001) and null (Hallstrom, Lapidus, Bengtsson, \& Edstrom, 1986; Vogt, Pope, Mullooly, \& Hollis, 1994) findings have been reported. Although little attention has been paid to MDD and all-cause mortality in 
veterans, our findings are consistent with those of one recent study in which individuals with a diagnosis of depression were at increased risk of death over an average of two years (Kinder, et al., 2008).

Some studies have examined the prognostic importance of both symptoms of anxiety and depression and mortality in cardiac patient groups. In a review of 25 studies of chronic heart failure patients, anxiety symptoms were measured along with depression in just three studies (Pelle, Gidron, Szabo, \& Denollet, 2008). Anxiety symptoms were not associated with mortality, whereas depressive symptoms significantly predicted death (Pelle, et al., 2008). A number of studies have examined both anxiety and depression symptoms and mortality in myocardial infarction patients. High depression and anxiety scores have both been found to predict all-cause mortality (Herrmann et al., 1998), and cardiac death (Denollet \& Brutsaert, 1998). However, in three studies, symptoms of depression but not anxiety in multivariate models predicted all-cause or cardiac mortality (Ahern et al., 1990; Frasure-Smith \& Lesperance, 2003; Frasure-Smith, Lesperance, \& Talajic, 1995). Finally, neither depression nor anxiety symptoms were found to predict mortality in myocardial infarction patients (Lane, Carroll, Ring, Beevers, \& Lip, 2001). Thus, in prognostic studies, it would appear that depressive symptoms may be a more stable predictor of mortality than anxiety. However, it is unclear the extent to which the results of these studies of patients with chronic inflammatory disease relate to the present aetiological study where only $1 \%$ had a diagnosis of coronary heart disease at the medical examination. It is possible that the effects of depression on mortality and the underlying mechanisms may not be identical in patient versus population-based studies. Further, none of the prognostic studies that we know of have examined psychiatric comorbidity effects on mortality.

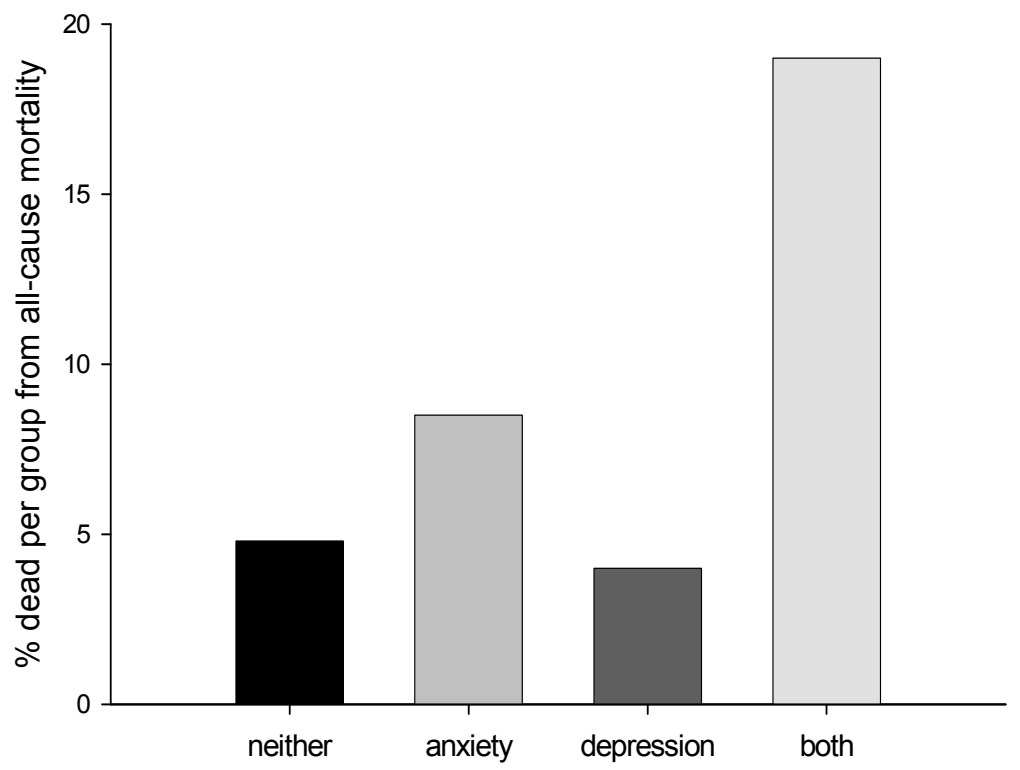

Fig. 2. Percentage deceased in each diagnosis category 
GAD and MDD are highly comorbid psychiatric conditions (Kessler, Chiu, et al., 2005). In the present study, $3.6 \%$ of participants had a diagnosis of both MDD and GAD. More strikingly, 55\% of those with a diagnosis of MDD also had GAD. Patients with comorbid MDD and GAD have been found to have poorer functional status than those with either condition alone (Kessler, DuPont, Berglund, \& Wittchen, 1999) and it has been proposed that they are at increased risk for CVD (Sevincok, Buyukozturk, \& Dereboy, 2001). However, we know of no previous studies that have examined the mortality risk associated with this comorbidity. The present analysis indicates that comorbid MDD and GAD confers a stronger mortality risk than either condition alone. The importance of comorbidity was further demonstrated in the supplementary analyses of the effects of comorbidity with PTSD where it was the comorbidity of MDD and GAD, and of PTSD, MDD, and GAD that emerged as the most consistent predictors of mortality. Consequently, this argues that comorbidity should receive considerably more attention in future research on mental disorders and health outcomes, at least in studies of non-patient groups. Further, clinical interventions have tended to concentrate on single mental health diagnoses; these findings suggest that targeting comorbidity might be a fruitful new approach.

\subsection{Limitations}

It should be conceded that there are a number of limitations to this analysis and its interpretation. First, the weaker effects for CVD in comparison to all-cause mortality may reflect the small number of deaths due to CVD in this sample resulting in lower power to detect significant associations, particularly when adjusting for a large number of covariates. Support for this assertion can be found in the hazard ratios which were of comparable size in the fully adjusted models for both all-cause and CVD mortality, but only attained significance when all-cause mortality was the outcome. Second, residual confounding as a consequence of un-measured variables cannot be wholly discounted. The present analysis, however, did adjust for a large number of potential confounding variables. Third, as this sample was exclusively male, there is the issue of generalisation. It should be noted that the previous studies with null results tested women only in one case (Hallstrom et al., 1986) and both sexes in the other (Vogt et al., 1994). It is also worth noting, though, that these studies had much smaller samples, reducing their power to detect effects on mortality. In addition, it is possible that veterans differ in other ways from the broader population. For example, one study of stable coronary heart disease that included veterans found no evidence that depression was associated with elevated levels of inflammation (Whooley et al., 2007); a finding opposite to that of many studies in non-cardiac disease patients. However, not all the patients in this study were veterans (Whooley et al., 2007). Fourth, it has been suggested that the prevalence of mental health disorders in the Vietnam Experience Study are underestimated (Dohrenwend et al., 2006, 2007). However, this criticism has mainly been levelled at estimations of PTSD prevalence. Nevertheless, it is possible that severely depressed veterans were less likely to participate in the medical examination, which may have accounted for the attenuated associations for major depression in the present analyses. However, this seems unlikely given that only $10(<2 \%)$ veterans were unable to attend on the basis of physical/mental disability, and only $372(<6 \%)$ refused to attend, with the main reasons being a lack of interest or unwillingness to travel. Moreover, underestimation in the present study would make the associations demonstrated between MDD, GAD, their comorbidity and mortality more compelling. Fifth, given that a diagnosis of MDD only requires two weeks of 
symptoms, whereas GAD requires symptoms for at least six months, it is possible that MDD diagnoses were less trustworthy. However, evidence indicates that the DSM-III criteria for diagnosis of both MDD and GAD are highly reliable (Riskind et al., 1987).

In conclusion, the present analysis in Vietnam veterans showed that MDD and GAD were positively associated with all-cause and CVD mortality. However, in the fully adjusted analyses reported, the relationships with CVD mortality were non-significant, possibly due to low statistical power. A diagnosis of both MDD and GAD proved much the strongest predictor of all-cause and CVD mortality. The effects of comorbidity of MDD and GAD, and with PTSD would suggest that future research on mental health disorders and physical health outcomes, as well as future clinical interventions, should pay more attention to comorbidity. In addition, future studies should attempt to measure and take account of a full range of factors likely to be associated with both mental and physical health.

\section{GAD and the metabolic syndrome}

The metabolic syndrome (MetS) is a prevalent cluster of symptoms (obesity, high triglyceride levels, low levels of HDL cholesterol, raised blood pressure, and high levels of fasting blood glucose or a diagnosis of diabetes) (Isomaa et al., 2001; Lakka et al., 2002; Thomas et al., 2007; Trevisan, Liu, Bahsas, \& Menotti, 1998). As the metabolic syndrome increases risk for cardiovascular and all-cause mortality (Isomaa, et al., 2001; Lakka, et al., 2002; Thomas, et al., 2007; Trevisan, et al., 1998), recently there has been interest in the relationship between it and various mental health disorders.

The bulk of this research has focused on depression and although contrary indications exist (Herva et al., 2006), there is evidence of a positive association between depression and the metabolic syndrome (Dunbar et al., 2008; Heiskanen et al., 2006; Kinder, Carnethon, Palaniappan, King, \& Fortmann, 2004; Koponen, Jokelainen, Keinanen-Kiukaanniemi, Kumpusalo, \& Vanhala, 2008; McCaffery, Niaura, Todaro, Swan, \& Carmelli, 2003; Raikkonen, Matthews, \& Kuller, 2002; Skilton, Moulin, Terra, \& Bonnet, 2007; Vaccarino et al., 2008). However, the vast majority of these studies were concerned with depressive symptoms; a recent review (Goldbacher \& Matthews, 2007) identified only two studies examining MDD in this context. In a small study of outpatients, those who still had a diagnosis at 6-year follow-up showed a higher prevalence of the metabolic syndrome (Heiskanen, et al., 2006). In a larger scale study, a history of MDD was associated with the metabolic syndrome in women but not men (Kinder, et al., 2004). Much less attention has been paid to anxiety and the metabolic syndrome and the three most recent studies reported null findings (Herva, et al., 2006; Raikkonen, Matthews, \& Kuller, 2007; Skilton, et al., 2007). However, an earlier study of women found an association between the metabolic syndrome and increased anxiety seven years later (Raikkonen, et al., 2002). These studies have all been concerned with anxiety symptoms; no study has tested the association with GAD. We were able to utilise the Vietnam Experience Study dataset in order to examine the potential links between GAD and the metabolic syndrome. In this dataset, the metabolic syndrome was defined as having at least three of: BMI $>30 \mathrm{~kg} / \mathrm{m}^{2}$ (in the absence of waist circumference data, BMI at this threshold is regarded by World Health Organization as an acceptable substitute in defining MetS); triglycerides $\geq 1.7$ $\mathrm{mmol} / 1(150 \mathrm{mg} / \mathrm{dl})$; HDL cholesterol < $1.036 \mathrm{mmol} / 1(40 \mathrm{mg} / \mathrm{dl})$; blood pressure $\geq$ $130 / 85 \mathrm{mmHg}$ or taking antihypertensive medication; fasting glucose $\geq 6.1 \mathrm{mmol} / 1$ (110 $\mathrm{mg} / \mathrm{dl}$ ) or taking diabetes medication. 


\subsection{Associations with the metabolic syndrome}

Seven hundred and seventy-three $(18 \%)$ of the men in the Vietnam Experience Study were identified as having the metabolic syndrome. Aside from differing on all the components of the metabolic syndrome, participants with it were slightly older, had lower IQ scores and a briefer education, were less likely to be divorced, widowed or separated and more likely to come from ethnic groups other than white or black, i.e. Hispanic. Full details of the characteristics of those with and without the metabolic syndrome are shown in Table 3.

\begin{tabular}{|c|c|c|c|c|c|}
\hline & \multicolumn{2}{|c|}{$\begin{array}{l}\text { Metabolic syndrome } \\
\quad(\mathrm{N}=773)\end{array}$} & \multicolumn{2}{|c|}{$\begin{array}{c}\text { No metabolic syndrome } \\
(\mathrm{N}=3483)\end{array}$} & \multirow[t]{2}{*}{$p$} \\
\hline & Mean & SD & Mean & SD & \\
\hline \multicolumn{6}{|l|}{ Metabolic Syndrome Markers: } \\
\hline BMI $(\mathrm{kg} / \mathrm{m} 2)$ & 30.00 & 4.16 & 25.03 & 2.96 & $<.001$ \\
\hline Triglycerides (mg/dL) & 214.20 & 151.22 & 91.97 & 56.70 & $<.001$ \\
\hline HDL cholesterol (mg/dL) & 34.85 & 7.78 & 46.85 & 12.24 & $<.001$ \\
\hline $\mathrm{SBP}(\mathrm{mmHg})$ & 131.46 & 11.87 & 121.13 & 11.25 & $<.001$ \\
\hline $\mathrm{DBP}(\mathrm{mmHg})$ & 91.16 & 8.64 & 82.56 & 8.88 & $<.001$ \\
\hline Blood glucose $(\mathrm{mg} / \mathrm{dL})$ & 104.57 & 28.06 & 92.04 & 12.35 & $<.001$ \\
\hline \multicolumn{6}{|l|}{ Covariates: } \\
\hline Age at medical examination (years) & 38.67 & 2.51 & 38.25 & 2.51 & $<.001$ \\
\hline Units of alcohol per week & 6.69 & 15.46 & 7.17 & 14.18 & .40 \\
\hline Standardised IQ score from enlistment & 99.63 & 15.03 & 101.75 & 15.20 & $<.001$ \\
\hline \multirow[t]{2}{*}{ Grade achieved in education } & 13.04 & 2.26 & 13.35 & 2.31 & .001 \\
\hline & \multicolumn{2}{|c|}{$\mathrm{N}(\%)$} & \multicolumn{2}{|c|}{$\mathrm{N}(\%)$} & $p$ \\
\hline \multicolumn{6}{|l|}{ Metabolic Syndrome Markers: } \\
\hline Obese & \multicolumn{2}{|c|}{$396(51)$} & \multicolumn{2}{|c|}{$154(4)$} & $<.001$ \\
\hline Hypertension Diagnosis & \multicolumn{2}{|c|}{$189(24)$} & \multicolumn{2}{|c|}{$252(7)$} & $<.001$ \\
\hline Diabetes Diagnosis & \multicolumn{2}{|c|}{$27(4)$} & \multicolumn{2}{|c|}{$22(1)$} & $<.001$ \\
\hline \multicolumn{6}{|l|}{ Predictor variables: } \\
\hline MDD & \multicolumn{2}{|c|}{$57(7)$} & \multicolumn{2}{|c|}{$220(6)$} & .28 \\
\hline GAD & \multicolumn{2}{|c|}{$94(12)$} & \multicolumn{2}{|c|}{$317(9)$} & .009 \\
\hline \multicolumn{6}{|l|}{ Covariates: } \\
\hline $\begin{array}{rr}\text { lace of service } & \text { Ever in Vietnam } \\
\text { Other overseas } \\
\text { US only }\end{array}$ & \multicolumn{2}{|c|}{$\begin{array}{l}195(21) \\
134(17)\end{array}$} & \multicolumn{2}{|c|}{$\begin{array}{l}900(26) \\
678(19)\end{array}$} & .29 \\
\hline $\begin{array}{r}\text { White } \\
\text { Black } \\
\text { Other }\end{array}$ & & & & & .005 \\
\hline $\begin{array}{|rr|}\text { Household income in midlife } & <\$ 20,000 \\
& -\$ 40,000 \\
& >\$ 40,000\end{array}$ & & & & & .35 \\
\hline $\begin{array}{r}\text { Non smoker } \\
\text { Ex smoker } \\
\text { Current smoker }\end{array}$ & & & & & .85 \\
\hline \begin{tabular}{|rr} 
Marital Status: & Married \\
Divorced/separated/widowed \\
Never married
\end{tabular} & & & & & $<.001$ \\
\hline
\end{tabular}

Table 3. Characteristics of those with and without the metabolic syndrome 
In this sample, MDD was not significantly associated with the metabolic syndrome in either age-adjusted analyses or those adjusting for other confounding variables described above. However, there was a positive association between GAD and the metabolic syndrome, such that those with GAD were 1.36 times more likely to have the metabolic syndrome than those without GAD diagnosis. Depression and anxiety are highly co-morbid conditions, and in the present sample, MDD and GAD were significantly correlated, $\mathrm{C}(1)=.38, \mathrm{p}<.001$, and 153 $(4 \%)$ were diagnosed with both conditions. Consequently, in competitive models, entering MMD alone, GAD alone, and their co-morbidity simultaneously, only GAD was associated with metabolic syndrome incidence.

These findings contrast with the results of previous studies, however, these have been concerned with symptoms of anxiety and the analysis reported above is the first to examine GAD in the context of the metabolic syndrome. Further, only two studies, to date, have explored the links between MDD and the metabolic syndrome $(5,7)$. The much larger of these two studies reported an association with MDD in women, but not men (Kinder, et al., 2004). Thus, the apparent discrepancy between the present findings and those of others may be more illusory than real. Of the components of the metabolic syndrome, it was hypertension, obesity, and triglycerides that differentiated those with and without GAD. There was no association with diabetes.

\subsection{Limitations and potential mechanisms}

Unfortunately, with cross-sectional analyses it is impossible to determine the direction of the association and whether it is causal. If anxiety precedes metabolic syndrome, there are at least two pathways through which it might contribute to its aetiology. First, anxiety has been associated with unhealthy behaviour, such as smoking, binge drinking, physical inactivity, and unhealthy diet (Strine et al., 2008). However, despite the fact that participants with GAD consumed more units of alcohol per week and were more likely to be current smokers, the present association between GAD and metabolic syndrome was unaffected by adjustment for smoking and alcohol consumption. Second, it has been postulated that hypothalamic-pituitary-adrenocortical dysregulation associated with affective disorders, including anxiety, may contribute over time to the metabolic syndrome (Raikkonen, et al., 2002). There is evidence linking anxiety with altered cortisol activity; high levels of anxiety symptoms were found to be associated with a less pronounced cortisol awakening response (Therrien et al., 2008). However, it remains possible that the causal pathway is from the metabolic syndrome to GAD. The metabolic syndrome has been shown to predict symptoms of anxiety seven years later (Raikkonen, et al., 2002), whereas the reverse was not found (Raikkonen, et al., 2002, 2007). Further, it is reasonable to presume that diagnosis of some of the components of the metabolic syndrome may be anxiolytic. For example, irrespective of actual blood pressure levels, perceived hypertensive status was positively associated with anxiety (Spruill et al., 2007). Whatever the underlying mechanism of the association with GAD, it remains true that depression has been the main focus for studies of mental health and physical health outcomes. The current data suggest that future research should perhaps pay equal attention to GAD.

The present analyses may have other limitations. The generalisability of the sample, being wholly male was raised above. A recent review concluded that evidence relating depression to the metabolic syndrome was stronger for women than men (Goldbacher \& Matthews, 2007). Our failure to find an association for depression might also reflect lower power, since 
there were fewer participants with MDD than GAD, as discussed above. Finally, although we adjusted for many possible confounders, residual confounding as a consequence of poorly measured or unmeasured variables cannot be wholly discounted. For example, both GAD and MetS are associated with poor sleep quality (Tyrer \& Baldwin, 2006; Jennings et al., 2007). Future studies should not only pay more attention to GAD as a serious predictor of health outcomes, but also take into account health behaviours such as sleep quality.

\section{GAD and hypertension}

Despite the health risks associated with hypertension (Chiong, 2008), few studies have examined whether mental health disorders can contribute to hypertension risk. Nothing is known about the association between GAD and hypertension, although three studies have examined the association between hypertension and symptoms of anxiety. Whereas the National Health and Nutrition Examination Survey (NHANES) (Jonas, Franks, \& Ingram, 1997) and the Framingham study (Markovitz, Matthews, Kannel, Cobb, \& D'Agostino, 1993) both observed a positive prospective association between symptoms of anxiety and hypertension, the Coronary Artery Risk Development in Young Adults (CARDIA) study reported no consistent relationship between the two (Yan et al., 2003). However, the measures of anxiety used in these studies were not synonymous with a clinical diagnosis of GAD. Similarly, few studies have examined the relationship between MDD and hypertension. However, there is at least some cross-sectional and prospective evidence of a positive association (Patten et al., 2005; Patten et al., 2009). GAD and MDD are highly comorbid, and as outlined above, both GAD and its co-morbidity with MDD predicted both all-cause and cardiovascular disease mortality, and GAD was also related to metabolic syndrome incidence. Using the Vietnam Experience Study again, it was hypothesised that both GAD and MDD would be linked to hypertension. It was also hypothesised that hypertension would be particularly prevalent among those with co-morbid MDD and GAD. At the medical examination in 1986, with the participant in a sitting position, a registered nurse, using a standard mercury sphygmomanometer to blood pressure measured, twice consecutively, from both arms. For analysis, an average of the two right arm values was computed. Measurements from the left arm were used to verify individual results. Hypertension was defined by having one of the following: a reported physician-diagnosis at interview; reported taking antihypertensive medication; an average systolic blood pressure $\geq 140 \mathrm{mmHg}$; an average diastolic blood pressure $\geq 90 \mathrm{mmHg}$ at the medical examination. There were 441 participants who indicated during the telephone interview that they had a physician diagnosis of hypertension and a further 98 who, although not reporting a diagnosis of hypertension, indicated that they were taking antihypertensive medication. Others have encountered individuals without an acknowledged diagnosis of hypertension who report taking antihypertensive medication and have designated them as hypertensive (Patten et al., 2009). The remainder and majority $(\mathrm{N}=842)$ of those classified as hypertensive was as a result of the blood pressure assessment at the medical examination. This suggests that there was substantial undiagnosed and/or untreated hypertension. As our outcome measure is hypertension, it is essential to include participants with a physician diagnosis of hypertension in that outcome. Of the participants with a diagnosis of hypertension, 292 $(66 \%)$ were taking anti-hypertensive medication. The effect of this would be to lower blood pressure, such that some of these participants $(\mathrm{N}=108)$ no longer met a criterion solely based on measured blood pressure. Nevertheless, they are still rightly regarded as suffering from hypertension. 


\subsection{Associations with hypertension}

One thousand, three hundred, and eighty-one (33\%) of the veterans were classified as hypertensive. Veterans who were older, black, had served in Vietnam, were non smokers, had a relatively high BMI, and consumed more units of alcohol per week, and had lower household income in midlife were more likely to be hypertensive. The characteristics of those with and without hypertension are shown in Table 4.

\begin{tabular}{|c|c|c|c|c|c|}
\hline & \multicolumn{2}{|c|}{$\begin{array}{c}\text { Hypertensive } \\
(\mathrm{N}=1381)\end{array}$} & \multicolumn{2}{|c|}{$\begin{array}{l}\text { Normotensive } \\
\quad(\mathrm{N}=2801)\end{array}$} & \multirow[t]{2}{*}{$p$} \\
\hline & Mean & SD & Mean & SD & \\
\hline $\mathrm{SBP}(\mathrm{mmHg})$ & 132.80 & 12.01 & 118.07 & 8.69 & $<.001$ \\
\hline $\mathrm{DBP}(\mathrm{mmHg})$ & 93.42 & 8.19 & 79.40 & 6.05 & $<.001$ \\
\hline Age at medical examination (years) & 38.57 & 2.48 & 38.20 & 2.54 & $<.001$ \\
\hline BMI $\left(\mathrm{kg} / \mathrm{m}^{2}\right)$ & 27.64 & 4.28 & 25.07 & 3.13 & $<.001$ \\
\hline \multirow[t]{2}{*}{ Alcohol consumption (units/week) } & 8.89 & 18.42 & 6.26 & 12.03 & $<.001$ \\
\hline & \multicolumn{2}{|c|}{$\mathrm{N}(\%)$} & \multicolumn{2}{|c|}{$\mathrm{N}(\%)$} & $p$ \\
\hline $\begin{array}{rr}\text { Place of service } & \begin{array}{r}\text { Ever in Vietnam } \\
\text { Other overseas } \\
\text { US only }\end{array} \\
\end{array}$ & \multicolumn{2}{|c|}{$\begin{array}{l}342(25) \\
221(16)\end{array}$} & \multicolumn{2}{|c|}{$1491(53)$} & $<.001$ \\
\hline Ethnicity & & & & & $<.001$ \\
\hline Education grade & \multicolumn{2}{|c|}{$529(38)$} & & & .08 \\
\hline \begin{tabular}{rr|} 
Household income in midlife & $<\$ 20,000$ \\
& $-\$ 40,000$ \\
& $>\$ 40,000$
\end{tabular} & \multicolumn{2}{|c|}{$676(49)$} & \multicolumn{2}{|c|}{$\begin{array}{c}752(27) \\
1420(51)\end{array}$} & .01 \\
\hline $\begin{array}{r}\text { Non smoker } \\
\text { Ex smoker } \\
\text { Current smoker }\end{array}$ & \multicolumn{2}{|c|}{$\begin{array}{l}393(28) \\
400(29)\end{array}$} & & & .001 \\
\hline $\begin{array}{rr}\text { Marital Status: } & \text { Married } \\
\text { Divorced/separated/widowed } \\
\text { Never married }\end{array}$ & \multicolumn{2}{|c|}{$\begin{array}{l}991(72) \\
257(19)\end{array}$} & & & .10 \\
\hline Predictor Variables: & & & & & \\
\hline GAD & \multicolumn{2}{|c|}{$171(12)$} & \multicolumn{2}{|c|}{$232(8)$} & $<.001$ \\
\hline MDD & \multicolumn{2}{|c|}{$121(9)$} & & & $<.001$ \\
\hline
\end{tabular}

Table 4. Characteristics of those with and without hypertension

Both GAD and MDD were associated with an elevated risk of hypertension in fully-adjusted models, although the association was stronger for MDD than GAD on this occasion. Of the participants with co-morbid GAD and MDD, 72 (47\%) were hypertensive. Both GAD, MDD, and comorbidity were associated with an increased risk of hypertension in age-adjusted analyses, but when adjusting for all other covariates, only comorbidity was significantly related to hypertension, although there was a trend for a relationship with GAD $(p=.06)$.

Given that antihypertensive medication can be prescribed for conditions other than hypertension, hypertension was redefined based on only physician diagnosis and measured blood pressure. This reduced the sample to 4180 and the numbers classified as hypertensive as 1329 (32\%). In the separate fully adjusted models, both GAD and MDD were positively associated with hypertension defined in this alternative fashion. 
However, in the fully adjusted comorbidity competitive analysis, no statistically significant relationships emerged. The only association to approach significance was between co-morbidity and hypertension.

Over $30 \%$ of the sample met the main criteria for hypertension. This proportion is somewhat higher than that reported from studies with participants of a similar mean age (e.g., Patten, et al., 2009). However, in part this could reflect different definitions of hypertension; relying solely on reported diagnostic and medication status, and not including measured blood pressure, will almost certainly lead to an underestimate of prevalence. In addition, the present sample was clustered at the low end of the socio-economic spectrum. This might also help explain their relatively high prevalence of hypertension. Other analyses indicate an inverse gradient between socio-economic status and measured blood pressure, although a less consistent association between socio-economic position and hypertension treatment rates (Colhoun, Hemingway, \& Poulter, 1998). In the present sample, however, household income in midlife was associated with hypertension.

Both GAD and MDD were positively associated with hypertension. The latter result is consistent with the cross-sectional and prospective outcomes from the Canadian National Population Health Survey (Patten et al., 2005; Patten, et al., 2009). We know of no previous studies that have examined the relationship between GAD and hypertension. However, a positive association between symptoms of anxiety and hypertension has been reported from NHANES and the Framingham study (Jonas, et al., 1997; Markovitz, et al., 1993), although no such relationship emerged from analysis of data from the CARDIA study (Yan, et al., 2003). In fully adjusted competitive analysis, we found that only the co-morbidity of GAD and MDD was significantly associated with an increased risk of hypertension. It is possible that co-morbidity signals more severe psychiatric dysfunction and that it is the severity of dysfunction that is associated with physical health outcomes, similar to the findings for mortality above. However, it is also possible that comorbidity reflects a greater negative disposition, and it is this which is associated with hypertension (Suls \& Bunde, 2005). Whatever the case, given the high comorbidity of GAD and MDD, it is perhaps regrettable that studies of psychiatric disorders and physical health have focused almost exclusively on single disorders.

\subsection{Limitations and mechanisms}

Although we are not able to determine causality from the present cross-sectional associations, the prospective associations between MDD and hypertension (Patten et al., 2009) and symptoms of anxiety and hypertension studies (Jonas et al., 1997; Markovitz et al., 1993), cited above, make it unlikely that GAD or MDD are a psychological response to hypertension diagnosis. There are several putative pathways through which disorders such as GAD and MDD might contribute to development of hypertension. In addition, in the majority of instances in the present study, hypertension was apparently undiagnosed. Further, many of the sample had served in Vietnam. As a life event, a diagnosis of hypertension is likely to pale by comparison. The two most cited are unhealthy behaviours and physiological dysregulation. In the present analyses, the associations were still evident following adjustment for two of the most prominent unhealthy behaviours, smoking and high levels of alcohol consumption. That smokers have lower blood pressure and that alcohol consumption is positively related to hypertension are common observations (Beilin, 1987; Green, Jucha, \& Luz, 1986). Although we have no data directly pertaining to the second route, others have observed altered activity of the hypothalamic- 
pituitary-adrenal axis in approximately $50 \%$ of depressed patients (Brown, Varghese, \& McEwen, 2004), which, in turn, may increase the risk of hypertension (Torpy, Mullen, Ilias, \& Nieman, 2002).

Other limitations of this analysis are that, as discussed above, the present study's participants were all men and so there is the issue of generalisation. Indeed, in the Framingham study, symptoms of anxiety predicted hypertension in middle-aged men but not middle-aged women (Markovitz et al., 1993). Accordingly, the associations reported here may pertain only for men. In addition, the present participants were largely from the lower end of the socio-economic spectrum and thus our findings may not generalise to the population as a whole. However, these analyses again indicate the importance of GAD, as well as MDD in terms of health outcomes, and particular their comorbidity.

\section{Conclusion}

In conclusion, the analyses discussed above indicated that both GAD and MDD were individually positively related to all-cause mortality and to hypertension in male Vietnamera veterans. However, the strongest association with both mortality and hypertension was observed for co-morbid GAD and MDD. Further, when considering another major health outcome, the metabolic syndrome, GAD but not MDD was associated with an increased prevalence of this constellation of symptoms. Depression has been the main focus for studies of psychiatric disorders and physical health outcomes. The current data suggest that future research should perhaps pay equal attention to GAD and, for some outcomes, it seems that it is particularly its co-morbidity with MDD and/or other mental disorders which might predict poorer health. Future research remains to determine the mechanisms underlying these associations with health outcomes, through prospective assessment and a thorough inclusion of both biological and behavioural covariates.

\section{Acknowledgment}

Mortality surveillance of the cohort in the post-service VES was funded by the National Center for Environmental Health, Atlanta, US. The Medical Research Council (MRC) Social and Public Health Services Unit receives funding from the MRC and the Chief Scientist Office at the Scottish Government Health Directorates. The author would also like to acknowledge the involvement of Professor Douglas Carroll, Dr Catharine Gale, and Dr G. David Batty in the analyses reported

\section{References}

Ahern, D. K., Gorkin, L., Anderson, J. L., Tierney, C., Hallstrom, A., Ewart, C., et al. (1990). Biobehavioral variables and mortality or cardiac arrest in the Cardiac Arrhythmia Pilot Study (CAPS). American Journal of Cardiology, Vol.66, pp.59-62.

American Psychiatric Association, (1980). Diagnostic and statistical manual of mental disorders (3rd. edition). American Psychiatric Association, Washington DC.

Batty, G. D., Shipley, M. J., Mortensen, L., Boyle, S. H., Barefoot J, Grønbaek, M., et al. (2008). IQ in late adolescence/early adulthood, risk factors in middle-age, and later allcause mortality in men: the Vietnam Experience Study. Journal of Epidemiology and Community Health, Vol.62, pp.522-531. 
Beilin, L. J. (1987). Epidemiology of alcohol and hypertension. Adv Alcohol Subst Abuse, Vol.6, 69-87.

Boscarino, J. A. (1997). Diseases among men 20 years after exposure to severe stress: implications for clinical research and medical care. Psychosomatic Medicine, Vol.59, pp.605-614.

Boscarino, J. A. (2004). Posttraumatic stress disorder and physical illness: results from clinical and epidemiologic studies. Annals of the New York Academy of Sciences, Vol.1032, pp.141-153.

Boscarino, J. A. (2006a). External-cause mortality after psychologic trauma: the effects of stress exposure and predisposition. Comparative Psychiatry, Vol.47, pp.503-514.

Boscarino, J. A. (2006b). Posttraumatic stress disorder and mortality among U.S. Army veterans 30 years after military service. Annals of Epidemiology, Vol.16, pp.248-256.

Boscarino, J. A., \& Chang, J. (1999). Higher abnormal leukocyte and lymphocyte counts 20 years after exposure to severe stress: research and clinical implications. Psychosomatic Medicine, Vol.61, pp.378-386.

Brown, E. S., Varghese, F. P., \& McEwen, B. S. (2004). Association of depression with medical illness: does cortisol play a role? Biological Psychiatry, Vol.55, pp.1-9.

Chiong, J.R. (2008). Controlling hypertension from a public health perspective. International Journal of Cardiology, Vol. 127, pp.151-156.

Colhoun, H. M., Hemingway, H., \& Poulter, N. R. (1998). Socio-economic status and blood pressure: an overview analysis. Journal of Human Hypertension, Vol.12, pp.91-110.

Denollet, J., \& Brutsaert, D. L. (1998). Personality, disease severity, and the risk of long-term cardiac events in patients with a decreased ejection fraction after myocardial infarction. Circulation, Vol.97, pp.167-173.

Dohrenwend, B.P., Turner, J.B., Turse, N.A., Adams, B.G., Koenen, K.C., \& Marshall, R. (2006). The psychological risks of Vietnam for U.S. veterans: a revisit with new data and methods. Science, Vol.313, pp.979-82.

Dohrenwend, B.P., Turner, J.B., Turse, N.A., Adams, B.G., Koenen, K.C., \& Marshall, R. (2007). Continuing controversy over the psychological risks of Vietnam for U.S. veterans. Journal of Trauma and Stress, Vol.20, pp.449-65.

Dunbar, J. A., Reddy, P., Davis-Lameloise, N., Philpot, B., Laatikainen, T., Kilkkinen, A., et al. (2008). Depression: an important co morbidity with metabolic syndrome in a general population. Diabetes Care, Vol.31, pp.2368-2373.

Eaker, E. D., Sullivan, L. M., Kelly-Hayes, M., D'Agostino, R. B., Sr., \& Benjamin, E. J. (2005). Tension and anxiety and the prediction of the 10-year incidence of coronary heart disease, atrial fibrillation, and total mortality: the Framingham Offspring Study. Psychosomatic Medicine, Vol.67, pp.692-696.

Frasure-Smith, N., \& Lesperance, F. (2003). Depression and other psychological risks following myocardial infarction. Archives of General Psychiatry, Vol.60, 627-636.

Frasure-Smith, N., Lesperance, F., \& Talajic, M. (1995). The impact of negative emotions on prognosis following myocardial infarction: is it more than depression? Health Psychology, Vol.14, 388-398.

Gaylord, K. M. (2006). The psychosocial effects of combat: the frequently unseen injury. Critical Care Nursing Clinician North America, Vol.18, pp.349-357. 
Goldbacher, E. M., \& Matthews, K. A. (2007). Are psychological characteristics related to risk of the metabolic syndrome? A review of the literature. Annals of Behavioral Medicine, Vol.34, 240-252.

Green, M. S., Jucha, E., \& Luz, Y. (1986). Blood pressure in smokers and nonsmokers: epidemiologic findings. American Heart Journal, Vol.111, pp.932-940.

Haines, A. P., Imeson, J. D., \& Meade, T. W. (1987). Phobic anxiety and ischaemic heart disease. BMJ, Vol.295, pp.297-299.

Hallstrom, T., Lapidus, L., Bengtsson, C., \& Edstrom, K. (1986). Psychosocial factors and risk of ischaemic heart disease and death in women: a twelve-year follow-up of participants in the population study of women in Gothenburg, Sweden. Journal of Psychosomatic Research, Vol.30, pp.451-459.

Hankin, C. S., Spiro, A., 3rd, Miller, D. R., \& Kazis, L. (1999). Mental disorders and mental health treatment among U.S. Department of Veterans Affairs outpatients: the Veterans Health Study. American Journal of Psychiatry, Vol.156, pp.1924-1930.

Heiskanen, T. H., Niskanen, L. K., Hintikka, J. J., Koivumaa-Honkanen, H. T., Honkalampi, K. M., Haatainen, K. M., et al. (2006). Metabolic syndrome and depression: a crosssectional analysis. Journal of Clinical Psychiatry, 67, pp.1422-1427.

Herrmann, C., Brand-Driehorst, S., Kaminsky, B., Leibing, E., Staats, H., \& Ruger, U. (1998). Diagnostic groups and depressed mood as predictors of 22-month mortality in medical inpatients. Psychosomatic Medicine, Vol.60, pp.570-577.

Herva, A., Rasanen, P., Miettunen, J., Timonen, M., Laksy, K., Veijola, J., et al. (2006). Cooccurrence of metabolic syndrome with depression and anxiety in young adults: the Northern Finland 1966 Birth Cohort Study. Psychosomatic Medicine, Vol.68, pp.213-216.

Hoge, C. W., Auchterlonie, J. L., \& Milliken, C. S. (2006). Mental health problems, use of mental health services, and attrition from military service after returning from deployment to Iraq or Afghanistan. Journal of the American Medical Association, Vol.295, pp.1023-1032.

Hoge, C. W., Castro, C. A., Messer, S. C., McGurk, D., Cotting, D. I., \& Koffman, R. L. (2004). Combat duty in Iraq and Afghanistan, mental health problems, and barriers to care. New England Journal of Medicine, Vol.351, pp.13-22.

Holwerda, T. J., Schoevers, R. A., Dekker, J., Deeg, D. J., Jonker, C., \& Beekman, A. T. (2007). The relationship between generalized anxiety disorder, depression and mortality in old age. International Journal of Geriatric Psychiatry, Vol.22, pp.241-249.

Isomaa, B., Almgren, P., Tuomi, T., Forsen, B., Lahti, K., Nissen, M., et al. (2001). Cardiovascular morbidity and mortality associated with the metabolic syndrome. Diabetes Care, Vol.24, pp.683-689.

Jennings, J.R., Muldoon, M.F., Hall, M., Buysse, D.J., \& Manuck, S.B. (2007). Self-reported sleep quality is associated with the metabolic syndrome. Sleep, Vol.30, pp.219-223.

Jonas, B. S., Franks, P., \& Ingram, D. D. (1997). Are symptoms of anxiety and depression risk factors for hypertension? Longitudinal evidence from the National Health and Nutrition Examination Survey I Epidemiologic Follow-up Study. Archives of Family Medicine, Vol.6, pp.43-49.

Kessler, R. C., Berglund, P., Demler, O., Jin, R., Merikangas, K. R., \& Walters, E. E. (2005). Lifetime prevalence and age-of-onset distributions of DSM-IV disorders in the 
National Comorbidity Survey Replication. Archives of General Psychiatry, Vol.62, pp.593-602.

Kessler, R. C., Chiu, W. T., Demler, O., Merikangas, K. R., \& Walters, E. E. (2005). Prevalence, severity, and comorbidity of 12-month DSM-IV disorders in the National Comorbidity Survey Replication. Archives of General Psychiatry,, Vol.62, pp.617-627.

Kessler, R. C., DuPont, R. L., Berglund, P., \& Wittchen, H. U. (1999). Impairment in pure and comorbid generalized anxiety disorder and major depression at 12 months in two national surveys. American Journal of Psychiatry, Vol.156, pp.1915-1923.

Kinder, L. S., Bradley, K. A., Katon, W. J., Ludman, E., McDonell, M. B., \& Bryson, C. L. (2008). Depression, posttraumatic stress disorder, and mortality. Psychosomatic Medicine, Vol.70, 20-26.

Kinder, L. S., Carnethon, M. R., Palaniappan, L. P., King, A. C., \& Fortmann, S. P. (2004). Depression and the metabolic syndrome in young adults: findings from the Third National Health and Nutrition Examination Survey. Psychosomatic Medicine, Vol.66, pp.316-322.

Koponen, H., Jokelainen, J., Keinanen-Kiukaanniemi, S., Kumpusalo, E., \& Vanhala, M. (2008). Metabolic syndrome predisposes to depressive symptoms: a populationbased 7-year follow-up study. Journal of Clinical Psychiatry, Vol.69, pp.178-182.

Lakka, H. M., Laaksonen, D. E., Lakka, T. A., Niskanen, L. K., Kumpusalo, E., Tuomilehto, J., et al. (2002). The metabolic syndrome and total and cardiovascular disease mortality in middle-aged men. Journal of the American Medical Association, Vol.288, pp.2709-2716.

Lane, D., Carroll, D., Ring, C., Beevers, D. G., \& Lip, G. Y. (2001). Mortality and quality of life 12 months after myocardial infarction: effects of depression and anxiety. Psychosomatic Medicine, Vol.63, pp.221-230.

Markovitz, J. H., Matthews, K. A., Kannel, W. B., Cobb, J. L., \& D'Agostino, R. B. (1993). Psychological predictors of hypertension in the Framingham Study. Is there tension in hypertension? Journal of the American Medical Association, Vol.270, pp.2439-2443.

McCaffery, J. M., Niaura, R., Todaro, J. F., Swan, G. E., \& Carmelli, D. (2003). Depressive symptoms and metabolic risk in adult male twins enrolled in the National Heart, Lung, and Blood Institute twin study. Psychosomatic Medicine, Vol.65, pp.490-497.

Murphy, J. M., Monson, R. R., Olivier, D. C., Sobol, A. M., \& Leighton, A. H. (1987). Affective disorders and mortality. A general population study. Archives of General Psychiatry, Vol.44, pp.473-480.

Musselman, D. L., Evans, D. L., \& Nemeroff, C. B. (1998). The relationship of depression to cardiovascular disease: epidemiology, biology, and treatment. Archives of General Psychiatry, Vol.55, pp.580-592.

O'Leary, D. A., \& Lee, A. S. (1996). Seven year prognosis in depression. Mortality and readmission risk in the Nottingham ECT cohort. British Journal of Psychiatry, Vol.169, pp.423-429.

Osby, U., Brandt, L., Correia, N., Ekbom, A., \& Sparen, P. (2001). Excess mortality in bipolar and unipolar disorder in Sweden. Archives of General Psychiatry, Vol.58, pp.844-850.

Patten, S. B., Beck, C. A., Kassam, A., Williams, J. V., Barbui, C., \& Metz, L. M. (2005). Longterm medical conditions and major depression: strength of association for specific 
conditions in the general population. Canadian Journal of Psychiatry, Vol.50, pp.195202.

Patten, S. B., Williams, J. V., Lavorato, D. H., Campbell, N. R., Eliasziw, M., \& Campbell, T. S. (2009). Major depression as a risk factor for high blood pressure: epidemiologic evidence from a national longitudinal study. Psychosomatic Medicine, Vol.71, pp.273279.

Pelle, A. J., Gidron, Y. Y., Szabo, B. M., \& Denollet, J. (2008). Psychological predictors of prognosis in chronic heart failure. Journal of Cardiac Failure, Vol.14, pp.341-350.

Prince, M., Patel, V., Saxena, S., Maj, M., Maselko, J., Phillips, M. R., et al. (2007). No health without mental health. The Lancet, Vol.370, pp.859-877.

Raikkonen, K., Matthews, K. A., \& Kuller, L. H. (2002). The relationship between psychological risk attributes and the metabolic syndrome in healthy women: antecedent or consequence? Metabolism, Vol.51, pp.1573-1577.

Raikkonen, K., Matthews, K. A., \& Kuller, L. H. (2007). Depressive symptoms and stressful life events predict metabolic syndrome among middle-aged women: a comparison of World Health Organization, Adult Treatment Panel III, and International Diabetes Foundation definitions. Diabetes Care, Vol.30, pp.872-877.

Reeves, R. R., Parker, J. D., \& Konkle-Parker, D. J. (2005). War-related mental health problems of today's veterans: new clinical awareness. Journal of Psychosocial Nursing and Mental Health Services, Vol.43, pp.18-28.

Riskind, J.H., Beck, A.T., Berchick, R.J., Brown, G., \& Steer, R.A. (1987). Reliability of DSMIII diagnoses for major depression and generalized anxiety disorder using the structured clinical interview for DSM-III. Archives of General Psychiatry, Vol.44, pp.817-20.

Robins, L., Helzer, J., \& Cottler, L. (1987). Diagnostic Interview Schedule (version III-A) Training Manual. Veterans Administration, St Louis.

Rugulies, R. (2002). Depression as a predictor for coronary heart disease. a review and metaanalysis. American Journal of Preventative Medicine, Vol.23, pp.51-61.

Sareen, J., Cox, B. J., Afifi, T. O., Stein, M. B., Belik, S. L., Meadows, G., et al. (2007). Combat and peacekeeping operations in relation to prevalence of mental disorders and perceived need for mental health care: findings from a large representative sample of military personnel. Archives of General Psychiatry, Vol.64, pp.843-852.

Sevincok, L., Buyukozturk, A., \& Dereboy, F. (2001). Serum lipid concentrations in patients with comorbid generalized anxiety disorder and major depressive disorder. Canadian Journal of Psychiatry, Vol.46, pp.68-71.

Skilton, M. R., Moulin, P., Terra, J. L., \& Bonnet, F. (2007). Associations between anxiety, depression, and the metabolic syndrome. Biological Psychiatry, Vol.62, pp.1251-1257.

Spruill, T. M., Pickering, T. G., Schwartz, J. E., Mostofsky, E., Ogedegbe, G., Clemow, L., et al. (2007). The impact of perceived hypertension status on anxiety and the white coat effect. Annals of Behavioral Medicine, Vol.34, pp.1-9.

Strine, T. W., Mokdad, A. H., Dube, S. R., Balluz, L. S., Gonzalez, O., Berry, J. T., et al. (2008). The association of depression and anxiety with obesity and unhealthy behaviors among community-dwelling US adults. General Hospital Psychiatry, Vol.30, pp.127137. 
Suls, J., \& Bunde, J. (2005). Anger, anxiety, and depression as risk factors for cardiovascular disease: the problems and implications of overlapping affective dispositions. Psychological Bulletin, Vol.131, pp.260-300.

Surtees, P. G., \& Barkley, C. (1994). Future imperfect: the long-term outcome of depression. British Journal of Psychiatry, Vol.164, pp.327-341.

The Centers for Disease Control Vietnam Experience Study, (1987). Postservice mortality among Vietnam veterans. Journal of the American Medical Association, Vol.257, pp.790-795.

The Centers for Disease Control Vietnam Experience Study, (1988a). Health status of Vietnam veterans. I. Psychosocial characteristics. Journal of the American Medical Association, Vol.259, pp.2701-2707.

The Centers for Disease Control Vietnam Experience Study, (1988b). Health status of Vietnam veterans. II. Physical Health. Journal of the American Medical Association, Vol.259, pp.2708-2714.

Therrien, F., Drapeau, V., Lupien, S. J., Beaulieu, S., Dore, J., Tremblay, A., et al. (2008). Awakening cortisol response in relation to psychosocial profiles and eating behaviors. Physiology of Behavior, Vol.93, pp.282-288.

Thomas, G. N., Schooling, C. M., McGhee, S. M., Ho, S. Y., Cheung, B. M., Wat, N. M., et al. (2007). Metabolic syndrome increases all-cause and vascular mortality: the Hong Kong Cardiovascular Risk Factor Study. Clinical Endocrinology, Vol.66, pp.666-671.

Torpy, D. J., Mullen, N., Ilias, I., \& Nieman, L. K. (2002). Association of hypertension and hypokalemia with Cushing's syndrome caused by ectopic ACTH secretion: a series of 58 cases. Annals of the New York Academy of Science, Vol.970, pp.134-144.

Trevisan, M., Liu, J., Bahsas, F. B., \& Menotti, A. (1998). Syndrome X and mortality: a population-based study. Risk Factor and Life Expectancy Research Group. American Journal of Epidemiology, Vol.148, 958-966.

Tyrer, P., \& Baldwin, D. (2006): Generalised anxiety disorder. The Lancet, Vol.368, pp.21562166.

Vaccarino, V., McClure, C., Johnson, B. D., Sheps, D. S., Bittner, V., Rutledge, T., et al. (2008). Depression, the metabolic syndrome and cardiovascular risk. Psychosomatic Medicine, Vol.70, pp.40-48.

van Hout, H. P., Beekman, A. T., de Beurs, E., Comijs, H., van Marwijk, H., de Haan, M., et al. (2004). Anxiety and the risk of death in older men and women. British Journal of Psychiatry, Vol.185, pp.399-404.

Vogt, T., Pope, C., Mullooly, J., \& Hollis, J. (1994). Mental health status as a predictor of morbidity and mortality: a 15-year follow-up of members of a health maintenance organization. American Journal of Public Health, Vol.84, pp.227-231.

Weissman, M. M., Markowitz, J. S., Ouellette, R., Greenwald, S., \& Kahn, J. P. (1990). Panic disorder and cardiovascular/cerebrovascular problems: results from a community survey. American Journal of Psychiatry, Vol.147, pp.1504-1508.

World Health Organisation, (1992). International Statistical Classification of Diseases and related health problems. WHO, Geneva.

Whooley, M.A., Caska, C.M., Hendrickson, B.E., Rourke, M.A., Ho, J., \& Ali, S. (2007). Depression and inflammation in patients with coronary heart disease: findings from the Heart and Soul Study. Biological Psychiatry, Vol.62, pp.314-20. 
Wulsin, L. R., Vaillant, G. E., \& Wells, V. E. (1999). A systematic review of the mortality of depression. Psychosomatic Medicine, Vol.61, pp.6-17.

Yan, L. L., Liu, K., Matthews, K. A., Daviglus, M. L., Ferguson, T. F., \& Kiefe, C. I. (2003). Psychosocial factors and risk of hypertension: the Coronary Artery Risk Development in Young Adults (CARDIA) study. Journal of the American Medical Association, Vol.290, pp.2138-2148. 


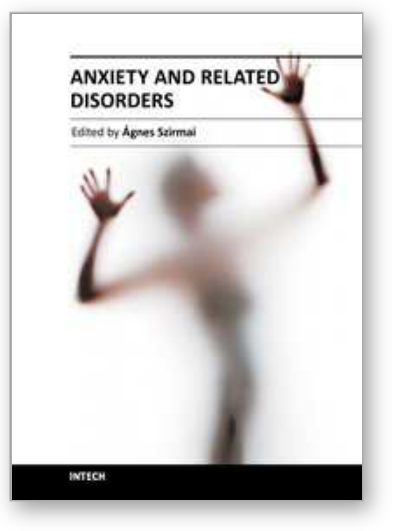

\author{
Anxiety and Related Disorders \\ Edited by Dr. Ãgnes Szirmai
}

ISBN 978-953-307-254-8

Hard cover, 292 pages

Publisher InTech

Published online 29, August, 2011

Published in print edition August, 2011

Anxiety disorders are one of the most common psychiatric disorders worldwide and many aspects of anxiety can be observed. Anxious patients often consult primary care physicians for their treatment, but in most cases they do not accept the diagnosis of anxiety disorder. Anxiety is a symptom that could be seen in many organic disorders and can accompany almost any psychiatric disorder. Anxiety disorders are frequent and are associated with significant distress and dysfunction. Stigmatization is an important factor in insufficient diagnosis. The problems of anxiety cover all fields of life. This book intends to describe the epidemiological aspects and the main co-morbidities and consecutive diseases of the anxiety disorders.

\title{
How to reference
}

In order to correctly reference this scholarly work, feel free to copy and paste the following:

Anna C. Phillips (2011). Generalised Anxiety Disorder, Mortality and Disease: A Stronger Predictor than Major Depressive Disorder, Anxiety and Related Disorders, Dr. Ãgnes Szirmai (Ed.), ISBN: 978-953-307-254-8, InTech, Available from: http://www.intechopen.com/books/anxiety-and-related-disorders/generalised-anxietydisorder-mortality-and-disease-a-stronger-predictor-than-major-depressive-disord

\section{INTECH}

open science | open minds

\section{InTech Europe}

University Campus STeP Ri Slavka Krautzeka 83/A 51000 Rijeka, Croatia Phone: +385 (51) 770447

Fax: +385 (51) 686166 www.intechopen.com

\section{InTech China}

Unit 405, Office Block, Hotel Equatorial Shanghai No.65, Yan An Road (West), Shanghai, 200040, China 中国上海市延安西路65号上海国际贵都大饭店办公楼 405 单元 Phone: +86-21-62489820

Fax: +86-21-62489821 
(C) 2011 The Author(s). Licensee IntechOpen. This chapter is distributed under the terms of the Creative Commons Attribution-NonCommercialShareAlike-3.0 License, which permits use, distribution and reproduction for non-commercial purposes, provided the original is properly cited and derivative works building on this content are distributed under the same license. 